Research Article

\title{
The Impact of PTPRK and ROS1 Polymorphisms on the Preeclampsia Risk in Han Chinese Women
}

\author{
Huihui Li $\mathbb{D}^{1,2,3}$ Xingyu Yan, ${ }^{4}$ Man Yang, ${ }^{5}$ Mei Liu, ${ }^{6}$ Shan Tian, ${ }^{7,8}$ Mengru Yu, ${ }^{7}$ \\ Wei-Ping Li, ${ }^{1,2}$ and Cong Zhang $\mathbb{D}^{1,2,5}$ \\ ${ }^{1}$ Center for Reproductive Medicine, Ren Ji Hospital, School of Medicine, Shanghai Jiao Tong University, Shanghai 200135, China \\ ${ }^{2}$ Shanghai Key Laboratory for Assisted Reproduction and Reproductive Genetics, Shanghai 200135, China \\ ${ }^{3}$ Center for Reproductive Medicine, Department of Obstetrics and Gynecology, Qilu Hospital of Shandong University, \\ Jinan 250012, China \\ ${ }^{4}$ Fujian Provincial Key Laboratory of Reproductive Health Research, Medical College of Xiamen University, Xiamen, \\ Fujian 361102, China \\ ${ }^{5}$ Shandong Provincial Key Laboratory of Animal Resistance Biology, College of Life Sciences, Shandong Normal University, \\ 88 East Wenhua Road, Jinan, Shandong 250014, China \\ ${ }^{6}$ Department of Obstetrics, Affiliated Hospital of Shandong University of Traditional Chinese Medicine, Jinan, \\ Shandong 250011, China \\ ${ }^{7}$ Center for Reproductive Medicine, Shandong Provincial Hospital Affiliated to Shandong University, \\ Shandong Provincial Key Laboratory of Reproductive Medicine, \\ National Research Center for Assisted Reproductive Technology and Reproductive Genetics, \\ The Key Laboratory for Reproductive Endocrinology of Ministry of Education, Jinan 250021, China \\ ${ }^{8}$ Center for Reproductive Medicine, Jinan Central Hospital, Jinan 250013, China
}

Correspondence should be addressed to Cong Zhang; zhangxinyunlife@163.com

Received 7 May 2021; Accepted 15 September 2021; Published 4 October 2021

Academic Editor: Thereza Maria Magalhães Moreira

Copyright (c) 2021 Huihui Li et al. This is an open access article distributed under the Creative Commons Attribution License, which permits unrestricted use, distribution, and reproduction in any medium, provided the original work is properly cited.

Objective. Preeclampsia (PE) is a severe complication in pregnancy and a leading cause of maternal and infant mortality. However, the exact underlying etiology of PE remains unknown. Emerging evidence indicates that the cause of PE is associated with genetic factors. Therefore, the aim of this study is to identify susceptibility genes to PE. Materials and Methods. Human Exome BeadChip assays were conducted using 370 cases and 482 controls and 21 loci were discovered. A further independent set of 958 cases and 1007 controls were recruited for genotyping to determine whether the genes of interest ROS1 and PTPRK are associated with PE. Immunohistochemistry was used for localization. Both qPCR and Western blotting were utilized to investigate the levels of PTPRK in placentas of $20 \mathrm{PE}$ and 20 normal pregnancies. Results. The allele frequency of PTPRK rs3190930 differed significantly between PE and controls and was particularly significant in severe PE subgroup and early-onset PE subgroup. PTPRK is primarily localized in placental trophoblast cells. The mRNA and protein levels of PTPRK in PE were significantly higher than those in controls. Conclusion. These results suggest that PTPRK appears to be a previously unrecognized susceptibility gene for PE in Han Chinese women, and its expression is also associated with PE, while ROS1 rs9489124 has no apparent correlation with PE risk.

\section{Introduction}

Preeclampsia (PE) is a severe complication in pregnancy and a leading cause of maternal and infant mortality; the worldwide PE incidence is $5-10 \%[1,2]$. PE is characterized by a new onset of hypertension and proteinuria after the 20th week of gestation. PE has been associated with abnormal differentiation and invasion of the trophoblast, widespread endothelial cell dysfunction, intravascular inflammation, impaired placental perfusion, oxidative stress, 
and angiogenesis imbalance [1]. However, the exact underlying etiology of PE remains unknown despite extensive efforts toward identifying the pathogenesis of PE.

Emerging evidence indicates that the cause of $\mathrm{PE}$ is associated with genetic factors since it was first expounded in the early 1960s [3, 4]. Pregnant mice lacking catechol-O-methyltransferase, Corin, atrial natriuretic peptide, or Elabela exhibit a PE-like phenotype [5-8]. In humans, geneticists [9] suggested that a single gene may possibly be responsible for $\mathrm{PE}$. Besides, $\mathrm{PE}$ has also been shown to aggregate in families [9]. Studies have shown that the general heritability of PE is estimated to be about $55 \%$, of which $35 \%$ is considered to be caused by maternal genetic factors, and $20 \%$ by fetal genetics [10]. Men born from preeclamptic pregnancy increase their partner's risk [11], which is perceived as a $13 \%$ contribution [10]. In addition, paternal obesity is the same as maternal obesity as a risk factor for PE [10]. Moreover, there is convincing evidence that the lead risk SNP rs4769613 from fetal Fms-like tyrosine kin (FLT1) is a risk factor for PE [12]. However, the present results remain controversial [13]. The genetic architecture behind PE is complex, as it includes maternal and fetal genes, genetically unfavorable combinations of maternal leukocyte receptors and fetal antigens, paternal factors, and any genetic conflict between the parents $[11,14,15]$. Therefore, a variety of candidate genes need to be investigated to identify the underlying causes of PE development.

To identify susceptibility genes, exome sequencing was conducted in a Han Chinese population, which identified several loci linked or associated with PE. Among these, SNP rs9489124 from c-ros oncogene 1 receptor tyrosine kinase (ROS1) and rs3190930 from protein tyrosine phosphatase receptor type $\mathrm{K}(P T P R K)$ were indicated as genetic risk factors for PE according to functional prediction. ROS1 is an orphan receptor tyrosine kinase of the insulin receptor family and a transmembrane protein with a typical tyrosine kinase sequence $[16,17]$. ROS1 has been confirmed as the gene of epithelial-mesenchymal interactions and has been shown to decrease the synthesis of extracellular matrix components in tissues [18]. Stimulation of the ROS1 receptor via phosphorylation has been associated with activated mitosis, morphological transformation, and epithelial cell migration $[19,20]$. PTPRK is a member of the protein tyrosine kinase family and plays an important role in the regulation of the tyrosine dephosphorylation of intracellular substrates [21]. It has been reported to be involved in the regulation of cell survival, proliferation, adhesion, and migration of specific cell types both in vitro and in vivo $[22,23]$. Furthermore, inactivation of PTPRK has been recently reported in several tumors [24], indicating that it can also act as a tumor suppressor by inhibiting cell cycle progression. However, the roles played by ROS1 and PTPRK in $\mathrm{PE}$ and their association with $\mathrm{PE}$ remain unknown to date.

Therefore, rs9489124 from ROS1 and rs3190930 from PTPRK were further genotyped in additional independent samples of 958 PE patients and 1007 controls in our replication study. Moreover, the expression of PTPRK in the placentas of $20 \mathrm{PE}$ and 20 normal pregnant women was also examined. The results indicate that PTPRK may be a susceptible candidate for PE.

\section{Materials and Methods}

2.1. Ethics Statement. The study was approved by the Ethics Committees of the First Affiliated Hospital of Nanjing Medical University, the Ethics Committees of the Second Affiliated Hospital of Nanjing Medical University, or the Ethics Committees of the Provincial Hospital Affiliated to Shandong University. Written informed consent to participate in this study was obtained from each patient.

2.2. Subjects. $370 \mathrm{PE}$ and 482 healthy controls were chosen for Human Exome BeadChip assays. A further $958 \mathrm{PE}$ women and 1007 healthy pregnant women were recruited for genotyping. All samples were collected from the First Affiliated Hospital of Nanjing Medical University, the Second Affiliated Hospital of Nanjing Medical University, and the Provincial Hospital Affiliated to Shandong University from December 2009 to February 2015. The controls were randomly selected from contemporaneous normotensive women without antenatal medical or obstetric complications and who delivered a healthy neonate at term (>37 weeks of gestation). PE was defined as a new onset of gestational hypertension (the presence of blood pressure values $\geq 140 / 90 \mathrm{~mm} \cdot \mathrm{Hg})$ and/or proteinuria ( $\geq 300 \mathrm{mg}$ within a $24 \mathrm{~h}$ urine collection and/or urine dipstick protein $\geq 1+$ ) after 20 weeks of gestation in previously normotensive and non-proteinuric women [25]. Severe PE (SPE) was defined as blood pressure $>160 / 110 \mathrm{mmHg}$ and/or $24 \mathrm{~h}$ urinary protein $\geq 5 \mathrm{~g}$ or urine dipstick protein $\geq 2+$ [25]. Early-onset PE was defined as PE manifestation prior to the 34 th gestational week and if it occurred thereafter, it was defined as late-onset PE. Exclusion criteria included major congenital anomalies, chronic hypertension, autoimmune disease, metabolic or cardiovascular disease, or renal disease. The placental tissues of normal pregnant women $(n=20)$ and PE patients $(n=20)$ were also obtained from the Provincial Hospital Affiliated to Shandong University.

2.3. Exome Sequencing and Quality Control (QC). DNA samples of 370 cases and 482 healthy controls were extracted from peripheral blood using $\mathrm{Wizard}^{\circledR}$ genomic DNA Purification Kit (Promega, Madison, WI, USA) following the manufacturer's protocol. The chip detection was entrusted to Emei Tongde Technology Development Co., Ltd. Briefly, intact genomic DNA $(>30 \mu \mathrm{g} / \mu \mathrm{l})$ with $\mathrm{A} 260 / 280 \geq 1.8$ was selected for Human Exome BeadChip assays (Illumina, San Diego, CA, USA). It contained 270241 SNPs that were used to uncover SNPs related to PE risk. The raw data of the chip scan was read using Illumina GenomeStudio software (V2011), and the preliminary screening was performed using the QC test to remove poor-quality SNP loci and individuals (i.e., pregnant women). Multivariable logistic regression analysis, adjusted for age, was performed to identify SNPs with $P<0.05$ that were significantly considered to be associated with $\mathrm{PE}$. The resulting SNPs were subjected to a further QC check to remove the following poor-quality variants: (1) call rate $<95 \%$, (2) Hardy-Weinberg equilibrium $P<10^{-3}$, and (3) SNPs in sex chromosomes. 
Susceptibility genes were identified after data analysis, combining their functions. Subsequently, genotyping was performed in the replication study to further verify the candidate genes using enlarged cohorts.

2.4. Genotyping. Genomic DNA was extracted from peripheral blood samples using the QIAamp DNA mini kit (Qiagen, NY, USA) according to the manufacturer's protocol. Both SNPs (rs9489124 from ROS1 and rs3190930 from PTPRK) were genotyped based on PCR assays in a thermal cycler (Bio-Rad Laboratories, USA). The PCR conditions were as follows: an initial denaturation step at $94^{\circ} \mathrm{C}$ for $5 \mathrm{~min} ; 35$ cycles of $30 \mathrm{~s}$ denaturation step at $95^{\circ} \mathrm{C}, 30 \mathrm{~s}$ annealing step at $58^{\circ} \mathrm{C}$, and a $45 \mathrm{~s}$ extension step at $72^{\circ} \mathrm{C}$; a $7 \mathrm{~min}$ final extension step was added at $72^{\circ} \mathrm{C}$. The primer sequences were ROS1 forward: $5^{\prime}$-ACT CTC CTT ACT GTT GC CCA CC- $3^{\prime}$ and reverse: $5^{\prime}$-ATG GCT TTT TAC CTG GAT TTA ATT AG- $3^{\prime}$; PTPRK forward: $5^{\prime}$-AAA GGG AGA AAA ATG CCA CGT- $3^{\prime}$ and reverse: $5^{\prime}$-GAA ACC TGT CCA TCT ATT GAG CC- $3^{\prime}$.

The PCR products were first analyzed via agarose gel electrophoresis and then sequenced using an automated sequencer (ABI PRISM 310; Applied Biosystems, CA, USA). The sequence variants were confirmed via three independent PCR runs, followed by sequencing in both directions.

2.5. Immunohistochemistry. Immunolocalization of PTPRK in human placental tissue was evaluated via indirect detection with the avidin: biotinylated-peroxidase complex kit (Vector Laboratories, Burlingame, CA, USA). In brief, paraffin-embedded tissue blocks were cut to $5 \mu \mathrm{m}$ thickness and mounted onto APES-coated slides. Antigen retrieval was performed using sodium citrate buffer solution $(10 \mathrm{mmol} / \mathrm{L}, \mathrm{pH} 6.5)$ prior to staining and endogenous peroxidase was quenched via $3 \% \mathrm{H}_{2} \mathrm{O}_{2}$ for $20 \mathrm{~min}$ at room temperature. Nonspecific binding was blocked with horse serum albumin and then, the tissue sections were probed with a goat antibody against an internal region of human PTPRK ( $4 \mu \mathrm{g} / \mathrm{ml}$; cat no. sc 30807 , Santa Cruz Biotechnology, TX, USA) overnight at $4^{\circ} \mathrm{C}$. The controls used pre-immune goat IgG for the primary antibody at the identical concentration. After three washes, tissue sections were incubated with a biotinylated universal antibody. The specific immunoreactivity was developed via 3-amino-9-ethylcarbazole (Vector Laboratories, Burlingame, CA, USA). Subsequently, the sections were counterstained with hematoxylin (Fisher Scientific, Pittsburg, PA, USA). Finally, the slides were mounted with neutral balsam, and then examined and digitally photographed using a BX53 F Olympus microscope (Olympus, Tokyo, Japan).

2.6. Western Blotting Analysis. Immunoblotting was conducted in accordance to the previously reported procedures [26-28]. $100 \mu \mathrm{g}$ protein extract of placental tissues was boiled at $95^{\circ} \mathrm{C}$ for $7 \mathrm{~min}$, then separated on $10 \%$ SDS polyacrylamide gel electrophoresis (SDS-PAGE), and electrically transferred to a polyvinylidene difluoride membrane with routine procedures. Subsequently, nonspecific binding was blocked with 5\% fat-free milk in Tris buffer for $60 \mathrm{~min}$. The membranes were first incubated with primary antibody against PTPRK (1:1000 dilution, Santa Cruz, USA) overnight at $4^{\circ} \mathrm{C}$, and then washed and incubated with horseradish peroxidase-conjugated secondary antibody. The protein was visualized using enhanced chemiluminescence (ECL) reagents from Amersham Biosciences (Piscataway, NJ, USA). All obtained values were normalized to the internal control ( $\beta$-actin, $1: 10000$ dilution, Abcam, UK). Immunoreactive signals were analyzed via densitometry using NIH Image-J imaging analysis software (Bethesda, MD, USA).

2.7. RNA Extraction and qPCR Assays. The total RNA of placental tissues was extracted using an RNA extraction kit (Takara Inc., Kusatsu, Japan). The RNA concentration was determined using a Nanodrop 2000c spectrophotometer (Thermo Scientific, Waltham, MA, USA) [29]. cDNA was synthesized via reverse transcriptase M-MuLV (Promega Inc., Canada) using $1 \mu \mathrm{g}$ of total RNA and following the manufacturer's protocols. To quantify PTPRK mRNA levels in placental tissues, qPCR assays were conducted in 96-well plates using SYBR ${ }^{\circledR}$ Green PCR Master Mix (Applied Biosystems Inc., NY, USA). Cycling conditions were as follows: pre-denaturation at $95^{\circ} \mathrm{C}$ for $2 \mathrm{~min}$, followed by 40 cycles of $95^{\circ} \mathrm{C}$ for $20 \mathrm{~s}, 60^{\circ} \mathrm{C}$ for $30 \mathrm{~s}, 72^{\circ} \mathrm{C}$ for $45 \mathrm{~s}$, and $7 \mathrm{~min}$ at $72^{\circ} \mathrm{C}$. All experiments were conducted in triplicate. Then, the levels of mRNA were normalized against those of $A C T B$ and analyzed according to the $2^{-\Delta \Delta \mathrm{Ct}}$ method. The sequence of PTPRK primers: forward: $5^{\prime}$-CTG CCT ACA ATG AAG GAG AAC G- $3^{\prime}$ and reverse: $5^{\prime}$-AAT CTC TAC CCG TGA ATC CAG T-3'.

2.8. Statistical Analysis. The obtained numerical variables of clinical characteristics of $\mathrm{PE}$ patients and controls are expressed as means \pm standard deviations (SD). Hardy-Weinberg equilibrium (HWE) tests were conducted using Haploview software (Broad Institute, Cambridge, MA, USA). Clinicopathological characteristics were compared via Student's $t$-test. The frequencies of alleles between PE cases and controls were compared via Chi-square test. Odds ratios (OR) and $95 \%$ confidence intervals (CIs) were calculated to assess the disease risk conferred by certain allele. Multiple hypothesis testing was carried out using the Benjamini-Hochberg method to control the false discovery rate (FDR) in unconditional logistic regression analysis. An FDR of 0.05 was exploited as a cut-off value to assess whether the obtained $P$ values were significant [30]. Binary logistic regression was conducted to adjust potential confounding covariates (maternal age). Values of $P<0.05$ are taken as statistically significant differences. Statistical analyses were conducted using SPSS statistical software (version 17.0; SPSS Inc., Chicago, IL, USA). 


\section{Results}

3.1. Clinicopathological Characteristics. The clinical characteristics of PE cases and controls are listed in Table 1. Women with $\mathrm{PE}$ had a higher mean maternal age $(P<0.05)$, BMI $(P<0.05)$, systolic blood pressure (SBP) $(P<0.05)$, diastolic blood pressure (DBP) $(P<0.05)$, and low gestational age rate than controls $(P<0.05)$. Moreover, the maternal age, BMI, SBP, DBP, primiparous percentage, and low gestational age percentage in the SPE and early-onset PE groups were significantly higher compared with their counterparts except BMI in the early-onset PE group, whereas the gestational age at birth and the fetal birth weight were significantly lower in the PE group than those in the controls, while the primiparous percentage and fetal sex were not significantly different in the PE group compared to control group.

3.2. Exome Sequencing and Gene Screening. After preliminary screening, 263,039 SNP loci and 851 pregnant women qualified, including 482 cases of normal pregnant women and 369 patients with SPE. Then, logistic regression was used to investigate the relationship between each SNP and SPE. All SNPs were classified according to minor allele frequency (MAF), OR value, and the $P$ value of the logistic regression. A total of 414 SNP sites were selected according to the criteria of $0.01<\mathrm{MAF}<0.05$ and $P<0.05$. Illumina GenomeStudio software was used for further quality inspection of these sites to remove sites of poor quality and those that were not in the exon region (although this is the exon chip, there are still many sites in non-exon regions). The remaining 331 loci are $\mathrm{OR}>1, P<0.05$, and $\mathrm{OR}<1$, $P<0.05$. Further screening of these genes for functions in proliferation, migration, invasion, recessive liver and kidney injuries, and angiogenesis identified 21 promising susceptibility genes (Table 2). Among these, ROS1 and PTPRK were selected for further study according to their functions. Thereafter, the rs9489124 from ROS1 and rs3190930 from PTPRK were genotyped in the replication study, using another larger cohort of samples.

3.3. ROS1 rs 9489124 and PTPRK rs3190930 Allele Frequencies in PE and Control Groups. The genetic polymorphism analyses of ROS1 rs9489124 and PTPRK rs3190930 were performed for $958 \mathrm{PE}$ patients and 1007 healthy controls. The genotype frequencies of both gene polymorphisms were all in Hardy-Weinberg equilibrium in both the PE and the control groups $(P<0.05)$, indicating a balance of population genetics data from the same Mendelian population.

The PTPRK rs3190930 allelic frequencies are presented in Table 3. The MAF differed significantly between the PE group and the control group $(P=0.033, \mathrm{OR}=1.995,95 \%$ $\mathrm{CI}=1.104-3.605)$. Relative to the controls, an association with rs3190930 was observed in women with SPE $(P=0.035$, $\mathrm{OR}=2.346,95 \% \mathrm{CI}=1.166-4.722)$ but not in women with mild PE $(P=0.120, \mathrm{OR}=1.763,95 \% \mathrm{CI}=0.896-3.466)$. MAF also differed significantly between early-onset $\mathrm{PE}$ and controls $(P=0.005, \quad \mathrm{OR}=3.271,95 \% \quad \mathrm{CI}=1.521-7.037)$, while no difference was found between late-onset $\mathrm{PE}$ and controls $(P=0.120, \mathrm{OR}=1.657,95 \% \mathrm{CI}=0.871-3.151)$.

To further explore the relationship between PTPRK rs3190930 and PE, the investigated cases were divided into four subgroups: early-onset mild PE (76 cases), early-onset SPE (127 cases), late-onset mild PE (499 cases), and lateonset SPE (256 cases). The MAF differed significantly between early-onset SPE and control groups $(P=0.004)$ (Table 4). No significant differences were found between the controls and other subgroups (Table 4). Additionally, as shown in Table 5, no significant differences were found for ROS1 rs9489124 allele frequencies between PE and control groups despite age adjustment $(P<0.05)$.

3.4. PTPRK Expression Changes in PE and Normal Human Placentas. To determine the distribution of PTPRK in human placentas, immunohistochemistry was conducted. PTPRK was found to localize in normal pregnancies and PE placentas (Figure 1). In placental villi, PTPRK was primarily present in syncytiotrophoblasts and cytotrophoblasts (Figures 1(a) and 1(c)). Furthermore, the mRNA levels of PTPRK were measured in human placentas. As depicted in Figure 2(a), the PTPRK mRNA was expressed at higher levels in the PE group than that in controls. To quantify the changes in the PTPRK protein in human placentas, Western blotting analysis was conducted. PTPRK was detected at $\sim 140 \mathrm{kDa}$ in human placental tissues (Figure 2(b)). When normalized to $\beta$-actin, the levels of the PTPRK protein were significantly increased $(P<0.01)$ in $\mathrm{PE}$ compared to controls (Figure 2(c)).

\section{Discussion}

The Human Genome Project has generated a wealth of data and contributes genetic information on common human disorders. Identifying the genetic contributions of complex diseases will advance diagnosis and therapy and will have far-reaching implications for public health [31]. The major tools of the Human Genome Project for the identification of disease susceptibility loci are the SNPs [31]. Whole exome sequencing is a powerful technique for the identification of novel genes of complex disorders [32]. Our recent exome sequencing identified 21 gene loci susceptible to $\mathrm{PE}$ and interestingly, two of these (ROS1 and PTPRK) had completely opposite functions. Then, replication studies were conducted on rs9489124 from ROS1 and rs3190930 from PTPRK to confirm their PE susceptibility in an independent and large cohort of Han Chinese women. Consequently, no variation in genetic background was found since all participants were Han Chinese women. A significant association between PTPRK rs3190930 and PE was identified. When the cases were divided into subgroups, statistically significant differences were also found between early-onset SPE and control groups. In contrast, no significant differences were observed between ROS1 rs9489124 and the risk of PE even after age adjustment. In addition, our data demonstrated that more cases of early-onset PE were SPE compared to late-onset PE. Moreover, maternal age, BMI, and 
TABLE 1: Clinicopathological characteristics of subjects (mean \pm SD).

\begin{tabular}{|c|c|c|c|c|c|c|}
\hline \multirow[b]{2}{*}{ Characteristics } & \multirow[b]{2}{*}{$\begin{array}{c}\text { Control } \\
(N=1007)\end{array}$} & \multirow[b]{2}{*}{$\mathrm{PE}(N=958)$} & \multicolumn{2}{|c|}{$\mathrm{PE}$} & \multicolumn{2}{|c|}{$\mathrm{PE}$} \\
\hline & & & $\operatorname{MPE}(N=575)$ & $\operatorname{SPE}(N=383)$ & $\begin{array}{l}\text { Early-onset } \\
(N=203)\end{array}$ & $\begin{array}{l}\text { Late-onset } \\
(N=755)\end{array}$ \\
\hline Maternal age (year) & $27.18 \pm 4.43$ & $28.83 \pm 5.67^{\mathrm{a}}$ & $28.12 \pm 5.35$ & $29.91 \pm 5.97^{\mathrm{b}}$ & $30.58 \pm 5.76$ & $28.36 \pm 5.56^{\mathrm{c}}$ \\
\hline $\begin{array}{l}\text { BMI (before } \\
\text { pregnancy) }\end{array}$ & $21.93 \pm 3.45$ & $23.47 \pm 3.78^{\mathrm{a}}$ & $23.13 \pm 3.83$ & $24.00 \pm 3.63^{\mathrm{b}}$ & $23.70 \pm 3.58$ & $23.41 \pm 3.83$ \\
\hline SBP (mmHg) & $117.40 \pm 8.17$ & $153.54 \pm 57.76^{\mathrm{a}}$ & $143.17 \pm 7.48$ & $169.11 \pm 88.70^{\mathrm{b}}$ & $167.47 \pm 121.43$ & $149.80 \pm 14.74^{\mathrm{c}}$ \\
\hline DBP (mmHg) & $74.23 \pm 6.88$ & $100.36 \pm 11.38^{\mathrm{a}}$ & $94.46 \pm 6.41$ & $109.22 \pm 11.48^{\mathrm{b}}$ & $106.70 \pm 13.80$ & $98.66 \pm 9.98^{\mathrm{c}}$ \\
\hline $\begin{array}{l}\text { Primiparous } \\
\text { percentage }\end{array}$ & 24.43 & 23.70 & 20.52 & $28.47^{\mathrm{b}}$ & 34.98 & $20.66^{\mathrm{c}}$ \\
\hline $\begin{array}{l}\text { Gestational time } \\
\text { (days) }\end{array}$ & $277.29 \pm 9.85$ & $264.81 \pm 17.99^{\mathrm{a}}$ & $266.04 \pm 16.57$ & $262.82 \pm 19.97^{\mathrm{b}}$ & $256.55 \pm 21.10$ & $267.63 \pm 15.88^{c}$ \\
\hline $\begin{array}{l}\text { Low gestational age } \\
\text { (percentage) }\end{array}$ & 3.18 & $25.47^{\mathrm{a}}$ & 18.09 & $36.55^{\mathrm{b}}$ & 63.05 & $15.36^{\mathrm{c}}$ \\
\hline Fetal weight (g) & $3431.36 \pm 1354.50$ & $3037.20 \pm 754.94^{\mathrm{a}}$ & $3161.73 \pm 677.95$ & $2852.46 \pm 823.51^{b}$ & $2281.09 \pm 881.27$ & $3217.23 \pm 594.16^{\mathrm{C}}$ \\
\hline Fetal sex $(\mathrm{F} / \mathrm{M})$ & $466 / 541$ & $492 / 466$ & $265 / 310$ & $201 / 182$ & $110 / 93$ & $356 / 399$ \\
\hline
\end{tabular}

Note: $\mathrm{PE}=$ preeclampsia; $\mathrm{MPE}=$ mild preeclampsia; $\mathrm{SPE}=$ severe preeclampsia; $\mathrm{BMI}=$ body mass index; $\mathrm{SBP}=$ blood pressure, systolic; $\mathrm{DBP}=$ blood pressure, diastolic. ${ }^{\mathrm{a} P} \mathrm{v}$ value $<0.05$ vs. control. ${ }^{\mathrm{b}} \mathrm{P}$ value $<0.05$ vs. MPE. ${ }^{\mathrm{c}} P$ value $<0.05$ vs. early-onset $\mathrm{PE}$.

TABLE 2: 21 susceptibility genes associated with PE in exome sequencing.

\begin{tabular}{|c|c|c|c|c|c|c|}
\hline Gene & Gene ID & Chromosome & MAF & OR & $P$ & Protein description \\
\hline COL16A1 & 1307 & 1 & 0.0464 & 2.03 & 0.00340 & Extracellular matrix \\
\hline COL11A2 & 1302 & 6 & 0.0223 & 2.59 & 0.00691 & Extracellular matrix \\
\hline COL6A2 & 1292 & 21 & 0.0117 & 2.71 & 0.04289 & Extracellular matrix \\
\hline SPARCL1 & 8404 & 4 & 0.0135 & 3.58 & 0.00683 & Extracellular matrix \\
\hline DOCK5 & 80005 & 8 & 0.0182 & 3.03 & 0.00621 & Guanyl-nucleotide exchange factor \\
\hline CYP2C9 & 1559 & 10 & 0.0481 & 1.90 & 0.00695 & Drug-metabolizing enzyme \\
\hline ROS1 & 6098 & 6 & 0.0334 & 1.84 & 0.02874 & Tyrosine kinase activity \\
\hline MAP4K5 & 11183 & 14 & 0.0428 & 1.77 & 0.02371 & Serine/threonine kinase activity \\
\hline AKAP9 & 10142 & 7 & 0.0170 & 2.64 & 0.0157 & Protein complex scaffold \\
\hline AKAP6 & 9472 & 14 & 0.0105 & 2.82 & 0.03814 & Ion channel and PKA binding \\
\hline AKAP11 & 11215 & 13 & 0.0199 & 2.09 & 0.04979 & Phosphatase 1 and PKA binding \\
\hline TRPM2 & 7226 & 21 & 0.0258 & 2.10 & 0.02180 & Transmembrane transporter activity \\
\hline ITPR3 & 3710 & 6 & 0.0188 & 2.20 & 0.03567 & Calcium release channel \\
\hline ITPRIPL1 & 150771 & 2 & 0.0381 & 1.71 & 0.04394 & ITPR3 interacting protein-like 1 \\
\hline NSUN5 & 55695 & 7 & 0.0288 & 3.13 & 0.00045 & DNA methyltransferase \\
\hline WBSCR22 & 114049 & 7 & 0.0152 & 3.72 & 0.00289 & DNA methyltransferase \\
\hline NOTCH4 & 4855 & 6 & 0.0199 & 2.70 & 0.00882 & Notch signaling protein \\
\hline$A P C D D 1 L$ & 164284 & 20 & 0.0370 & 1.87 & 0.02093 & Wnt signaling protein \\
\hline LGR5 & 8549 & 12 & 0.0141 & 2.58 & 0.03131 & Wnt signaling protein \\
\hline$M A F F$ & 23764 & 22 & 0.0329 & 0.26 & 0.00014 & Pitocin receptor- associated factor \\
\hline PTPRK & 5796 & 6 & 0.0211 & 0.33 & 0.00710 & Tyrosine phosphatase \\
\hline
\end{tabular}

Note: $\mathrm{MAF}=$ minor allele frequency; $\mathrm{OR}=$ odds ratio.

TABLE 3: Allele frequencies of PTPRK rs3190930 in women with and without PE.

\begin{tabular}{lcccccccc}
\hline rs3190930 & & Allele (T/C) & MAF & $P$ & $P_{\text {adjust }}$ & OR & $P_{\text {adjust }}^{a}$ & OR adjust $^{\text {a }}$ \\
\hline Control & & $17 / 1997$ & 0.008 & & & & & \\
PE & & $32 / 1884$ & 0.017 & 0.020 & 0.033 & $1.995(1.104-3.605)$ & 0.003 & $2.363(1.293-4.320)$ \\
PE & MPE & $17 / 1133$ & 0.015 & 0.096 & 0.120 & $1.763(0.896-3.466)$ & 0.074 & $1.871(0.940-3.725)$ \\
& SPE & $15 / 751$ & 0.020 & 0.014 & 0.035 & $2.346(1.166-4.722)$ & 0.002 & $3.220(1.552-6.683)$ \\
PE & Early-onset & $11 / 395$ & 0.027 & 0.001 & 0.005 & $3.271(1.521-7.037)$ & $<0.001$ & $4.778(2.108-10.833)$ \\
& Late-onset & $21 / 1489$ & 0.014 & 0.120 & 0.120 & $1.657(0.871-3.151)$ & 0.073 & $1.822(0.947-3.506)$ \\
\hline
\end{tabular}

Note: $\mathrm{PE}=$ preeclampsia; $\mathrm{MAF}=$ minor allele frequency; $\mathrm{OR}=$ odds ratio between case and control groups; $95 \% \mathrm{CI}=95 \%$ confidence interval. The $P_{\text {adjust }}$ value was obtained using the Benjamini-Hochberg method. $P_{\text {adjust }}^{a}$ value was adjusted by maternal age. 
TABLE 4: Allele frequencies of PTPRK rs3190930 in control, early-onset mild PE, early-onset severe PE, late-onset mild PE, and late-onset severe PE subjects.

\begin{tabular}{lccccccc}
\hline rs3190930 & Allele (T/C) & MAF & $P$ & $P_{\text {adjust }}$ & OR (95\%CI) & $P_{\text {adjust }}^{a}$ & OR $_{\text {adjust }}{ }^{\text {a }}$ \\
\hline Control & $17 / 1997$ & 0.008 & & & & & \\
Early-onset mild PE & $3 / 149$ & 0.020 & 0.160 & 0.320 & $2.365(0.685-8.162)$ & 0.122 & $2.780(0.761-10.517)$ \\
Early-onset severe PE & $8 / 246$ & 0.031 & 0.001 & 0.004 & $3.820(1.632-8.944)$ & $<0.001$ & $5.877(2.312-14.938)$ \\
Late-onset mild PE & $14 / 984$ & 0.014 & 0.153 & 0.204 & $1.671(0.820-3.404)$ & 0.154 & $1.692(0.820-3.489)$ \\
Late-onset severe PE & $7 / 505$ & 0.014 & 0.276 & 0.276 & $1.628(0.672-3.948)$ & 0.137 & $2.002(0.801-5.001)$ \\
\hline
\end{tabular}

Note: $\mathrm{PE}=$ preeclampsia; $\mathrm{MAF}=$ minor allele frequency; $\mathrm{OR}=$ odds ratio between case and control groups; $95 \% \mathrm{CI}=95 \%$ confidence interval. The $P_{\text {adjust }}$ value was obtained using the Benjamini-Hochberg method. ${ }^{\text {a The }} P$ value was adjusted by maternal age.

TABle 5: Allele frequencies of ROS1 rs9489124 in women with and without PE.

\begin{tabular}{lcccccrr}
\hline rs9489124 & & Allele (T/C) & MAF & $P$ & OR & $P_{\text {adjust }}^{a}$ & OR $_{\text {adjust }}^{\mathrm{a}}$ \\
\hline Control & & $30 / 1984$ & 0.015 & & & & \\
$\mathrm{PE}$ & & $39 / 1877$ & 0.020 & 0.193 & $1.374(0.850-2.221)$ & 0.178 & $1.400(0.856-2.311)$ \\
$\mathrm{PE}$ & $\mathrm{MPE}$ & $24 / 1126$ & 0.021 & 0.212 & $1.410(0.820-2.423)$ & 0.161 & $1.488(0.854-2.592)$ \\
& $\mathrm{SPE}$ & $15 / 751$ & 0.020 & 0.382 & $1.321(0.707-2.469)$ & 0.390 & $1.335(0.691-2.581)$ \\
$\mathrm{PE}$ & Early-onset & $8 / 398$ & 0.020 & 0.477 & $1.329(0.605-2.921)$ & 0.349 & $1.428(0.646-3.443)$ \\
& Late-onset & $31 / 1479$ & 0.021 & 0.204 & $1.386(0.835-2.300)$ & 0.190 & $1.417(0.841-2.385)$ \\
\hline
\end{tabular}

Note: $\mathrm{PE}=$ preeclampsia; $\mathrm{MAF}=$ minor allele frequency; $\mathrm{OR}=$ odds ratio between case and control groups; $95 \% \mathrm{CI}=95 \%$ confidence interval. ${ }^{\mathrm{a}}$ The $P$ value was adjusted by maternal age.

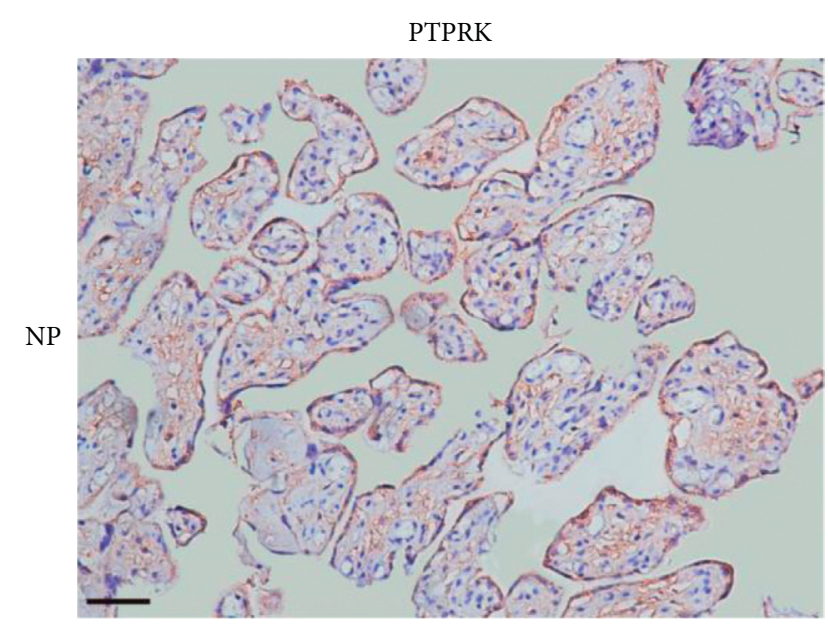

(a)

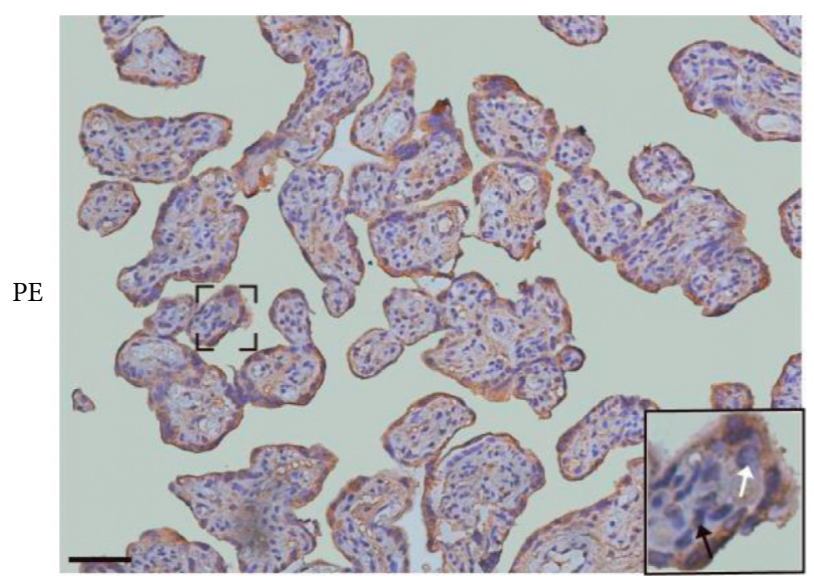

(c)

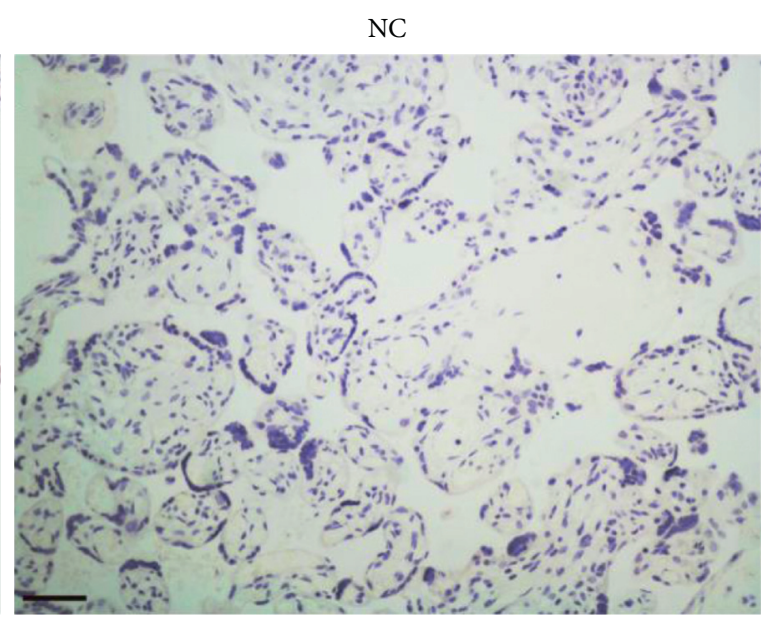

(b)

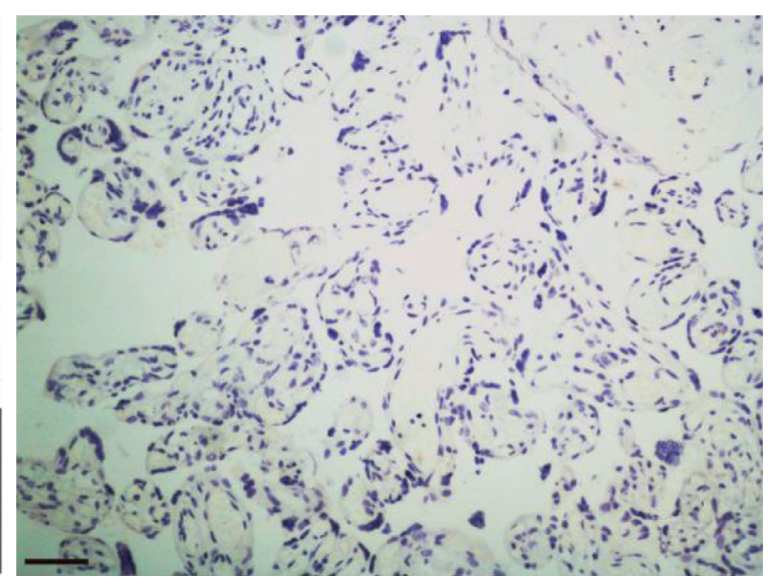

(d)

FIgURE 1: Immunolocalization of PTPRK in human placentas from normal pregnancies (NP) and preeclamptic (PE) pregnancies. (a, c) Brown staining of PTPRK. The tissue sections ( $n=20$ placentas for each group) were probed with PTPRK antibodies after hematoxylin counterstaining. (b, d) Negative control (NC). Preimmune IgG controls are shown in the right panel. The white arrow: syncytiotrophoblast. The black arrow: cytotrophoblast. Scale bars, $50 \mu \mathrm{m}$. 


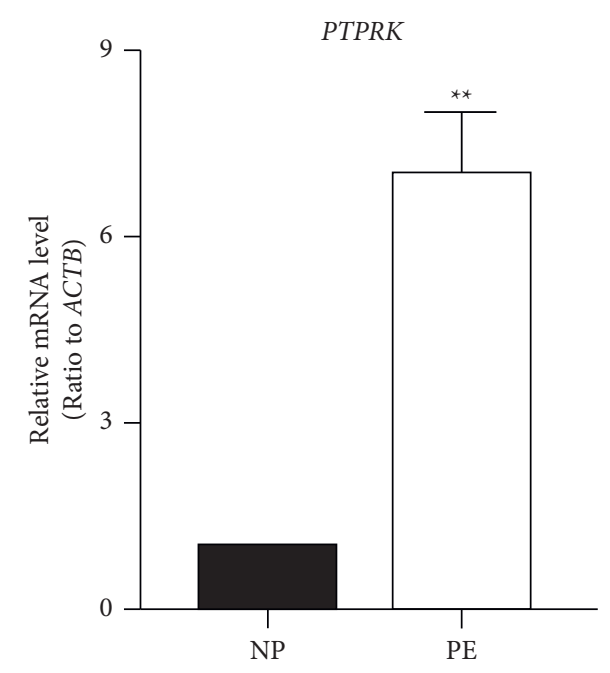

(a)

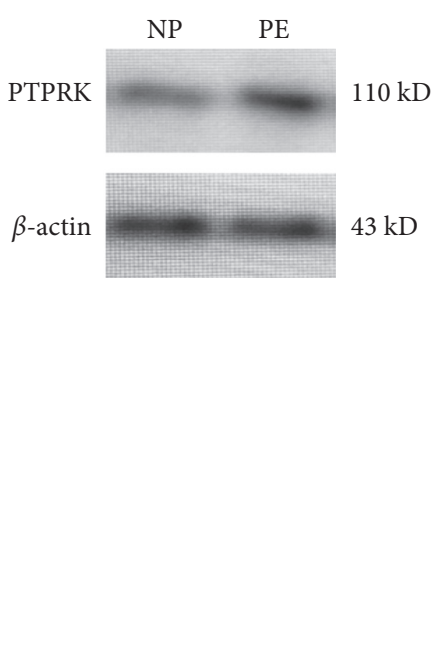

(b)

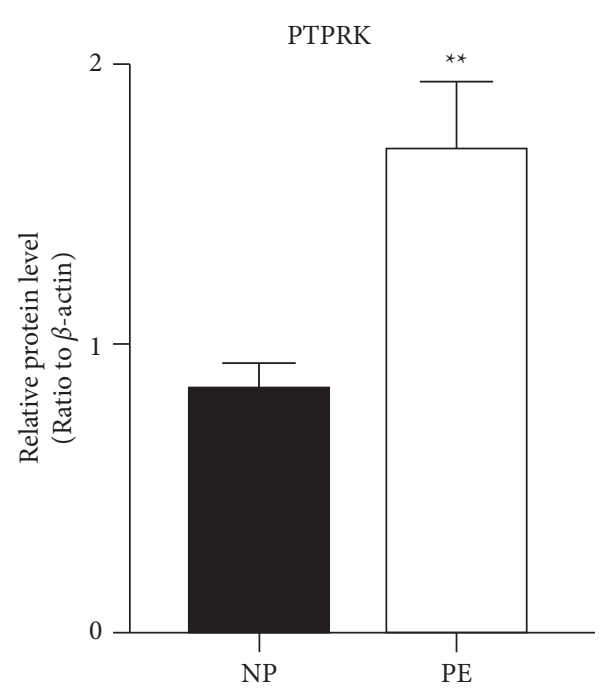

(c)

FIgURe 2: Expression patterns of PTPRK in human placentas. (a) QPCR analysis for PTPRK mRNA levels. The mRNA expression was determined using the $2^{-\Delta \Delta C t}$ method with $A C T B$ for normalization and was then compared to the control group $(n=20)$. (b, c) Western blotting analysis for the PTPRK protein levels (100 $\mathrm{g}$ of each placental sample) in human placentas from normal pregnancies (NP) and preeclamptic (PE) pregnancies. Representative blots are shown in (b), and the quantitative result is presented in (c). Data are expressed as mean \pm SD of three independent experiments. ${ }^{* *} P<0.01$.

primiparity are risk factors for PE, especially for SPE and early-onset $\mathrm{PE}$, which are consistent with previous studies [33-35].

$\mathrm{PE}$ is a complex disease during pregnancy. Hypoxia caused disruption of the angiogenic balance among vascular endothelial growth factor/placenta-derived growth factor and soluble Fms-like tyrosine kinase-1 (sFLT-1) is speculated to contribute to some of the maternal symptoms of $\mathrm{PE}$ [36-40]. Moreover, the absent or incomplete invasion of trophoblast cells into maternal spiral arteries has been suggested as initial steps in triggering PE [41]. Furthermore, it has been established that trophoblast invasion is influenced by a multitude of regulating factors such as adhesion molecules, cytokines, growth factors, proteases, and matrixderived components [42-44]. Human PTPRK locates on the long arm of chromosome 6q22-23 and has been indicated as a tumor suppressor $[21,45]$. Although the precise physiological role of PTPRK is still poorly understood, its ability to mediate homophilic or heterophilic interactions among cells together with the observation that the expression of PTPRK increases with increasing cell density, which strongly suggests that PTPRK plays a central role in the regulation of cellcell contact formation [46]. In addition, it has been reported that the expression of E-cadherin, which is a classical cell-cell adhesion molecule, is increased in interstitial and vascular EVT cells in patients with $\mathrm{PE}[47,48]$. Its expression, however, is reduced from the first trimester to the third trimester in normal term placentas [49]. Therefore, it has been suggested that the loss of E-cadherin is likely playing a key role in the EVT cell invasion of maternal spiral arteries [50]. PTPRK has been previously shown to be associated with E-cadherin/ $\beta$-catenin at the cell-cell contact area of adjacent cells, through dephosphorylation of E-cadherin/ $\beta$-catenin $[51,52]$. Reversible protein phosphorylation is a key regulatory mechanism in cell functions such as proliferation, differentiation, migration, and gene expression [53]. Thus, PTPRK appears to work as a molecular link between E-cadherin/ $\beta$-catenin, which is involved in both cell adhesion and gene transcription [52]. The epidermal growth factor receptor (EGFR) is a major proliferative pathway and PTPRK specifically and directly dephosphorylates EGFR, thus acting as a major negative regulator of EGFR signaling. Therefore, our results that showed that PTPRK was significantly increased in PE patients are consistent with previous research, which demonstrates the upregulation of PTPRK in PE inhibited beta-catenin and EGFR tyrosine phosphorylation and the subsequent suppression of cell growth $[52,54]$, which might be part of the PE pathogenesis. However, the relationship and interaction between PTPRK and the tyrosine kinase sFLT, which is closely related to PE, need to be further studied.

ROS1 elicits its regulatory effects through the binding and phosphorylating of multiple factors, then activating diverse signaling cascades, which is central for cell proliferation, differentiation, and survival [55]. ROS1 can activate STAT3, which is essential for oncogenic receptor RTKsdependent cell transformation [56]. It is also implicated in the stimulation of the PI3K/AKT signaling pathway, which is a canonical cascade that is responsible for both cell proliferation and growth [57]. Compelling evidence showed that ROS 1 can fuse with other genes, leading to protein kinase activation [58]. Several epithelial cancer types, including non-small-cell lung cancer, express activated fusion kinases that stimulate cancer progression [59]. These findings suggest that ROS1 and other proteins may act synergistically to mediate oncogenic function. However, ROS1 rs9489124 is 
not related to PE even after age adjustment. This means that the conducted exome sequencing experiment has a false positive result and requires more samples for verification. Future studies should evaluate associations between PE and further genetic variants.

This study has some limitations. First of all, the function of PTPRK has not been studied in depth. Secondly, due to the case-control study design, our study is not enough to provide causality, but only an association study. However, our findings do help predict PE risk.

\section{Conclusion}

In conclusion, the new susceptibility gene PTPRK has been identified for PE in Han Chinese women; moreover, the expression levels of PTPRK are related to PE; that is, both the expression levels and the polymorphisms of PTPRK are associated with PE. However, ROS1 SNP is not related to the risk of developing $\mathrm{PE}$ in the same population. The detailed pathogenic role of PTPRK in PE remains unclear and still requires functional studies in the future.

\section{Data Availability}

The data used to support the findings of this study are available from the corresponding author upon request.

\section{Conflicts of Interest}

The authors declare that they have no conflicts of interest regarding the publication of this paper.

\section{Authors' Contributions}

Huihui Li and Man Yang wrote the manuscript. Xingyu Yan collected and analyzed data. Mei Liu, Shan Tian, and Mengru Yu collected samples. Huihui Li designed and performed the study. Wei-Ping Li and Cong Zhang designed the study. Cong Zhang revised the language. All authors contributed to the article and approved the submitted version.

\section{Acknowledgments}

This study was supported by the National Key R\&D Program of China (2019YFA0802600) and the National Natural Science Foundation of China $(32170863,31871512$, and $31671199)$ to C. Z. Support was also received from grants from Shandong Provincial Key Research and Development Program (2018GSF118025) to H. L., Shanghai Commission of Science and Technology (17DZ2271100), and Open Project of Shandong Provincial Key Laboratory of Reproductive Medicine (SDKL2017018).

\section{References}

[1] B. W. J. Mol, C. T. Roberts, S. Thangaratinam, L. A. Magee, C. J. M. de Groot, and G. J. Hofmeyr, "Pre-eclampsia," The Lancet, vol. 387, no. 10022, pp. 999-1011, 2016.

[2] K. O. Osungbade and O. K. Ige, "Public health perspectives of preeclampsia in developing countries: implication for health system strengthening," Journal of Pregnancy, vol. 2011, Article ID 481095, 6 pages, 2011.

[3] L. C. Chesley, J. E. Annitto, and R. A. Cosgrove, "The familial factor in toxemia of pregnancy," Obstetrics \& Gynecology, vol. 32, no. 3, pp. 303-311, 1968.

[4] L. C. Chesley, R. A. Cosgrove, and J. E. Annitto, "Pregnancies in the sisters and daughters of eclamptic women," Obstetrics \& Gynecology, vol. 20, no. 1, pp. 39-46, 1962.

[5] K. Kanasaki, K. Palmsten, H. Sugimoto et al., "Deficiency in catechol-O-methyltransferase and 2-methoxyoestradiol is associated with pre-eclampsia," Nature, vol. 453, no. 7198, pp. 1117-1121, 2008.

[6] L. Ho, M. van Dijk, S. T. J. Chye et al., "ELABELA deficiency promotes preeclampsia and cardiovascular malformations in mice," Science, vol. 357, no. 6352, pp. 707-713, 2017.

[7] F. Werner, B. Kojonazarov, B. Gassner et al., "Endothelial actions of atrial natriuretic peptide prevent pulmonary hypertension in mice," Basic Research in Cardiology, vol. 111, no. 2, p. 22, 2016.

[8] Y. Cui, W. Wang, N. Dong et al., "Role of corin in trophoblast invasion and uterine spiral artery remodelling in pregnancy," Nature, vol. 484, no. 7393, pp. 246-250, 2012.

[9] L. C. Chesley and D. W. Cooper, "Genetics of hypertension in pregnancy: possible single gene control of pre-eclampsia and eclampsia in the descendants of eclamptic women," BJOG: An International Journal of Obstetrics and Gynaecology, vol. 93, no. 9, pp. 898-908, 1986.

[10] S. Cnattingius, M. Reilly, Y. Pawitan, and P. Lichtenstein, "Maternal and fetal genetic factors account for most of familial aggregation of preeclampsia: a population-based Swedish cohort study," American Journal of Medical Genetics, vol. 130A, no. 4, pp. 365-371, 2004.

[11] C. Galaviz-Hernandez, M. Sosa-Macias, and E. Teran, "Paternal determinants in preeclampsia," Frontiers in Physiology, vol. 9, p. 1870, 2018.

[12] K. J. Gray, R. Saxena, and S. A. Karumanchi, "Genetic predisposition to preeclampsia is conferred by fetal DNA variants near FLT1, a gene involved in the regulation of angiogenesis," American Journal of Obstetrics and Gynecology, vol. 218, no. 2, pp. 211-218, 2018.

[13] A. Ugwumadu, "The jury is still out on the genetics of preeclampsia," BJOG: An International Journal of Obstetrics and Gynaecology, vol. 128, no. 1, p. 66, 2020.

[14] J. Tong, Y. Niu, Z. J. Chen, and C. Zhang, "Comparison of the transcriptional profile in the decidua of early-onset and lateonset pre-eclampsia," Journal of Obstetrics and Gynaecology Research, vol. 46, no. 7, pp. 1055-1066, 2020.

[15] G. A. Dekker, "Pre-eclampsia - a disease of an individual couple," Pregnancy Hypertension: An International Journal of Women's Cardiovascular Health, vol. 4, no. 3, pp. 242-243, 2014.

[16] M. A. Lemmon and J. Schlessinger, "Cell signaling by receptor tyrosine kinases,” Cell, vol. 141, no. 7, pp. 1117-1134, 2010.

[17] R. Roskoski Jr., "ROS1 protein-tyrosine kinase inhibitors in the treatment of ROS1 fusion protein-driven non-small cell lung cancers," Pharmacological Research, vol. 121, pp. 202212, 2017.

[18] Z. Z. Liu, J. Wada, A. Kumar, F. A. Carone, M. Takahashi, and Y. S. Kanwar, "Comparative role of phosphotyrosine kinase domains ofc-rosandc-retProtooncogenes in metanephric development with respect to growth factors and matrix morphogens," Developmental Biology, vol. 178, no. 1, pp. 133-148, 1996. 
[19] M. Sachs, K. M. Weidner, V. Brinkmann et al., "Motogenic and morphogenic activity of epithelial receptor tyrosine kinases," Journal of Cell Biology, vol. 133, no. 5, pp. 1095-1107, 1996.

[20] Q. Xiong, J. L. Chan, C. S. Zong, and L. H. Wang, "Two chimeric receptors of epidermal growth factor receptor and c-Ros that differ in their transmembrane domains have opposite effects on cell growth," Molecular and Cellular Biology, vol. 16, no. 4, pp. 1509-1518, 1996.

[21] E. Fischer, H. Charbonneau, and N. Tonks, "Protein tyrosine phosphatases: a diverse family of intracellular and transmembrane enzymes," Science, vol. 253, no. 5018, pp. 401-406, 1991.

[22] N. K. Tonks, "Protein tyrosine phosphatases: from genes, to function, to disease," Nature Reviews Molecular Cell Biology, vol. 7, no. 11, pp. 833-846, 2006.

[23] M. Liu, S. Xie, and J. Zhou, "Use of animal models for the imaging and quantification of angiogenesis," Experimental Animals, vol. 67, no. 1, pp. 1-6, 2018.

[24] M. Matsushita, Y. Mori, K. Uchiumi et al., "PTPRKsuppresses progression and chemo-resistance of colon cancer cells via direct inhibition of pro-oncogenicCD133," FEBS Open Bio, vol. 9, no. 5, pp. 935-946, 2019.

[25] "Hypertension in pregnancy. Report of the American college of obstetricians and gynecologists' task force on hypertension in pregnancy," Obstetrics \& Gynecology, vol. 122, no. 5, pp. 1122-1131, 2013.

[26] S. Guo, X. Yan, F. Shi, K. Ma, Z.-J. Chen, and C. Zhang, "Expression and distribution of the zinc finger protein, SNAI3, in mouse ovaries and pre-implantation embryos," Journal of Reproduction and Development, vol. 64, no. 2, pp. 179-186, 2018.

[27] T. Guo, L. Zhang, D. Cheng et al., "Low-density lipoprotein receptor affects the fertility of female mice," Reproduction, Fertility and Development, vol. 27, no. 8, pp. 1222-1232, 2015.

[28] L.-1. Cui, G. Yang, J. Pan, and C. Zhang, "Tumor necrosis factor $\alpha$ knockout increases fertility of mice," Theriogenology, vol. 75, no. 5, pp. 867-876, 2011.

[29] N. Wang, H. Li, Y. Zhu, N. Li, Z.-J. Chen, and C. Zhang, "Melatonin protects against Epirubicin-induced ovarian damage," Journal of Reproduction and Development, vol. 66, no. 1, pp. 19-27, 2020.

[30] C. Wellcome Trust Case Control, "Genome-wide association study of 14,000 cases of seven common diseases and 3,000 shared controls," Nature, vol. 447, no. 7145, pp. 661-678, 2007.

[31] C. Newton-Cheh and J. N. Hirschhorn, "Genetic association studies of complex traits: design and analysis issues," $M u$ tation Research: Fundamental and Molecular Mechanisms of Mutagenesis, vol. 573, no. 1-2, pp. 54-69, 2005.

[32] S. Sanders, "Whole-exome sequencing: a powerful technique for identifying novel genes of complex disorders," Clinical Genetics, vol. 79, no. 2, pp. 132-133, 2011.

[33] L. C. Poon, A. Shennan, and J. A. Hyett, "The International Federation of Gynecology and Obstetrics (FIGO) initiative on pre-eclampsia: a pragmatic guide for first-trimester screening and prevention," International Journal of Obstetrics \& Gynaecology, vol. 145, pp. 1-33, 2019.

[34] C. Kabrhel, R. Varraso, S. Z. Goldhaber, E. B. Rimm, and C. A. Camargo, "Prospective study of BMI and the risk of pulmonary embolism in women," Obesity, vol. 17, no. 11, pp. 2040-2046, 2009.

[35] C. Pimentel, D. Solene, J. Frédérique, B. Guillaume, L. Jean, and L. Maëla, "What are the predictive factors for preeclampsia in oocyte recipients?" Journal of Human Reproductive Sciences, vol. 12, no. 4, p. 327, 2019.

[36] P. Vuorela, S. Helske, C. Hornig, K. Alitalo, H. Weich, and E. Halmesmäki, "Amniotic fluid-soluble vascular endothelial growth factor receptor-1 in preeclampsia," Obstetrics \& Gynecology, vol. 95, no. 3, pp. 353-357, 2000.

[37] R. J. Levine, S. E. Maynard, C. Qian et al., "Circulating angiogenic factors and the risk of preeclampsia," New England Journal of Medicine, vol. 350, no. 7, pp. 672-683, 2004.

[38] S. E. Maynard, J.-Y. Min, J. Merchan et al., "Excess placental soluble fms-like tyrosine kinase 1 (sFlt1) may contribute to endothelial dysfunction, hypertension, and proteinuria in preeclampsia," Journal of Clinical Investigation, vol. 111, no. 5, pp. 649-658, 2003.

[39] H. Sugimoto, Y. Hamano, D. Charytan et al., "Neutralization of circulating vascular endothelial growth factor (VEGF) by anti-VEGF antibodies and soluble VEGF receptor 1 (sFlt-1) induces proteinuria," Journal of Biological Chemistry, vol. 278, no. 15 , pp. $12605-12608,2003$.

[40] T. Krauss, H. U. Pauer, and H. G. Augustin, "Prospective analysis of placenta growth factor (PlGF) concentrations in the plasma of women with normal pregnancy and pregnancies complicated by preeclampsia," Hypertension in Pregnancy, vol. 23, no. 1, pp. 101-111, 2004.

[41] C. W. Redman and I. L. Sargent, "Latest advances in understanding preeclampsia," Science, vol. 308, no. 5728, pp. 1592-1594, 2005.

[42] L. Lunghi, M. E. Ferretti, S. Medici, C. Biondi, and F. Vesce, "Control of human trophoblast function," Reproductive Biology and Endocrinology, vol. 5, no. 1, p. 6, 2007.

[43] M. Knöfler, "Critical growth factors and signalling pathways controlling human trophoblast invasion," International Journal of Developmental Biology, vol. 54, no. 2-3, pp. 269280, 2010.

[44] Y. Q. Zhu, X. Y. Yan, and H. Li, "Insights into the pathogenesis of preeclampsia based on the features of placentation and tumorigenesis," Reproductive and Developmental Medicine, vol. 5, no. 2, p. 97, 2021.

[45] A. Barghorn, E. J. M. Speel, B. Farspour et al., "Putative tumor suppressor loci at 6q22 and 6q23-q24 are involved in the malignant progression of sporadic endocrine pancreatic tumors," American Journal Of Pathology, vol. 158, no. 6, pp. 1903-1911, 2001.

[46] J. Sap, Y. P. Jiang, D. Friedlander, M. Grumet, and J. Schlessinger, "Receptor tyrosine phosphatase R-PTP-kappa mediates homophilic binding," Molecular and Cellular Biology, vol. 14, no. 1, pp. 1-9, 1994.

[47] L. M. Brown, H. A. Lacey, P. N. Baker, and I. P. Crocker, "Ecadherin in the assessment of aberrant placental cytotrophoblast turnover in pregnancies complicated by preeclampsia," Histochemistry and Cell Biology, vol. 124, no. 6, pp. 499-506, 2005.

[48] H. W. Li, A. N. Y. Cheung, S. W. Tsao, A. L. M. Cheung, and W. S. O., "Expression of e-cadherin and beta-catenin in trophoblastic tissue in normal and pathological pregnancies," International Journal of Gynecological Pathology, vol. 22, no. 1, pp. 63-70, 2003.

[49] C. Floridon, O. Nielsen, and B. Holund, "Localization of E-cadherin in villous, extravillous and vascular trophoblasts during intrauterine, ectopic and molar pregnancy," Molecular Human Reproduction, vol. 6, no. 10, pp. 943-950, 2000.

[50] I. Shih, M. Y. Hsu, R. J. Oldt 3rd, M. Herlyn, J. D Gearhart, and R. J Kurman, "The role of E-cadherin in the motility and 
invasion of implantation site intermediate trophoblast," Placenta, vol. 23, no. 10, pp. 706-715, 2002.

[51] M. Fuchs, T. Müller, M. M. Lerch, and A. Ullrich, "Association of human protein-tyrosine phosphatase $\kappa$ with members of the armadillo family," Journal of Biological Chemistry, vol. 271, no. 28, pp. 16712-16719, 1996.

[52] L. Novellino, A. De Filippo, P. Deho et al., "PTPRK negatively regulates transcriptional activity of wild type and mutated oncogenic $\beta$-catenin and affects membrane distribution of $\beta$-catenin/E-cadherin complexes in cancer cells," Cellular Signalling, vol. 20, no. 5, pp. 872-883, 2008.

[53] A. J. Hale, E. Ter Steege, and J. den Hertog, "Recent advances in understanding the role of protein-tyrosine phosphatases in development and disease," Developmental Biology, vol. 428, no. 2, pp. 283-292, 2017.

[54] Y. Xu, L.-J. Tan, V. Grachtchouk, J. J. Voorhees, and G. J. Fisher, "Receptor-type protein-tyrosine phosphatase- $\kappa$ regulates epidermal growth factor receptor function," Journal of Biological Chemistry, vol. 280, no. 52, pp. 42694-42700, 2005.

[55] P. van der Geer, T. Hunter, and R. A. Lindberg, "Receptor protein-tyrosine kinases and their signal transduction pathways," Annual Review of Cell Biology, vol. 10, no. 1, pp. 251-337, 1994.

[56] C. S. Zong, L. Zeng, Y. Jiang, H. B. Sadowski, and L.-H. Wang, "Stat3 plays an important role in oncogenic Ros- and insulinlike growth factor I receptor-induced Anchorage-independent growth," Journal of Biological Chemistry, vol. 273, no. 43, pp. 28065-28072, 1998.

[57] J. Acquaviva, R. Wong, and A. Charest, "The multifaceted roles of the receptor tyrosine kinase ROS in development and cancer," Biochimica et Biophysica Acta (BBA)-Reviews on Cancer, vol. 1795, no. 1, pp. 37-52, 2009.

[58] A. Uguen and M. De Braekeleer, "ROS1 fusions in cancer: a review," Future Oncology, vol. 12, no. 16, pp. 1911-1928, 2016.

[59] I. M. El-Deeb, K. H. Yoo, and S. H. Lee, "ROS receptor tyrosine kinase: a new potential target for anticancer drugs," Medicinal Research Reviews, vol. 31, no. 5, pp. 794-818, 2011. 